\title{
Authorship, gender and geography in journals published by the Royal College of Psychiatrists
}

\author{
Mercy E. Ochuko-Emore, Julian Beezhold, ${ }^{1}$ Jide Morakinyo ${ }^{2}$
}

The Psychiatrist (2010), 34, 471-474, doi: 10.1192/pb.bp.109.027920

${ }^{1}$ Norfolk and Waveney Mental Health NHS Foundation Trust; ${ }^{2}$ East London NHS Foundation Trust

Correspondence to

Mercy E. Ochuko-Emore

(mercy.ochuko-emore@nwmhp.nhs.uk)

\begin{abstract}
Aims and method To determine female authorship of original articles and editorials between January 1997 and December 2008 in the British Journal of Psychiatry and the Psychiatric Bulletin. Editorials from Advances in Psychiatric Treatment and the geographical region of the female first author of original articles were also included in the study.
\end{abstract}

Results The gender was determined for $99.2 \%$ of the 2324 first authors of original articles and $100 \%$ of the 614 editorials. The percentage of original articles by female first authors fluctuated over the study period, ranging from 22.5 to $42.1 \%$ (mean 33.6) in the British Journal of Psychiatry, and from 25.5 to $46.8 \%$ (mean 37.6) in the Psychiatric Bulletin. There was a gross underrepresentation of females as first authors of editorials in all three journals. The percentage of female first authors of original articles from low- and middle-income countries ranged from 0.3 to $3.4 \%$ in both the British Journal of Psychiatry and the Psychiatric Bulletin.

\begin{abstract}
Clinical implications There is an increasing trend in female first authorship of original articles. However, females remain underrepresented, especially in editorials, in the British psychiatric journals examined. The representation of female first authors from low- and middle-income countries is disproportionately low. Strategies to address these inequalities should be implemented.
\end{abstract}

Declaration of interest M.E.O-E. is female.
The number of women entering and advancing in academic psychiatry remains significantly less than the number of men, ${ }^{1}$ despite the increasing number of women enrolling in medicine. ${ }^{2}$ A number of factors have been discussed in the literature to explain the underrepresentation of women in academic psychiatry; ${ }^{3}$ these include having few visible female role models and mentors, and the subtle cultural factors that seem to exclude women from the corridors of power. ${ }^{4}$ Other factors might include gender discrimination and the tendency for women's participation to decrease progressively as the selectivity and importance of the academic activity increases - the so-called 'glass ceiling effect'. ${ }^{5}$

An academic career in psychiatry is based on a triangle of clinical practice, research and publication, and teaching. ${ }^{6}$ Publication in peer-reviewed journals is an important indication of academic activity and measure of productivity; it is also highly emphasised in the academic promotion process $^{2}$ and to some extent in non-academic career advancement - hence the phrase 'publish or perish'. Traditionally, when a paper has multiple authors, the first author position is assigned to the person who contributed most significantly to the research/paper, ${ }^{7,8}$ indicating primary responsibility, leading role and active participation.

Studies in internal medicine and psychiatry have previously suggested that female faculty members are less likely than male colleagues to publish academic papers. ${ }^{9,10}$ However, some more recent studies have reported an increase in the number of female authors. ${ }^{11-14}$ AlonsoArroyo et al reported an increase from $29.92 \%$ in 1999 to $38.86 \%$ in 2006 of female authors in Actas Espanolas de Psiquiatria, with $34.02 \%$ of female first authors. ${ }^{11}$ Kurichi et al reported an increase from $11.1 \%$ in 1985 to $25.6 \%$ in 2003 of female first authors in Archives of Surgery. ${ }^{14}$ Jagsi et al found that the proportion of first authors who were females increased from $5.95 \%$ in 1970 to $29.3 \%$ in 2004 in academic medical literature. ${ }^{2}$ Alonso-Arroyo et $a l^{11}$ and Opgenhaffen et $a l^{12}$ studied female authorship in psychiatric literature but did not explore authorship of editorials.

In this study we aimed to determine the gender of all first authors of original articles and editorials published in the British Journal of Psychiatry and the Psychiatric Bulletin and editorials in Advances in Psychiatric Treatment from 1997 through 2008, and the geographical location of female first authors. All of these journals are peer reviewed and published by the Royal College of Psychiatrists. The British Journal of Psychiatry is one of the world's leading international journals, with a high impact factor. The Psychiatric Bulletin is also an international journal; it covers not only clinical aspects of psychiatry but also developments in psychiatric practice and service provision. Advances in Psychiatric Treatment is a bimonthly journal 
aimed primarily at promoting continuing professional development in psychiatry. The majority of editorials in all three journals are commissioned, but some are unsolicited. We hypothesised that over this 12-year period the proportion of female authorship would have increased.

\section{Method}

We examined all original articles and editorials published from January 1997 to December 2008 in the British Journal of Psychiatry and the Psychiatric Bulletin. Editorials in Advances in Psychiatric Treatment for the same period were also included in the study. British Journal of Psychiatry supplements were excluded as they cover selected areas and the editorial approach may differ significantly from the norm for the journal. International Psychiatry, also published by the Royal College of Psychiatrists, was excluded as it does not cover all of the study period. We determined the gender of the first author of each original article and editorial. Further information was collected regarding the discipline and geographical region, at the time of the publication, of female first authors of original articles.

The gender of the first authors was determined using a wide range of techniques, including personal knowledge, telephone contact, email contact, searching the General Medical Council website and using the Google internet search engine. In cases where the gender of the first author could not be determined, the authors were included in the total number of authors but excluded from the analysis.

We calculated the total number and percentage of articles by female first authors for each year and for each journal. The percentages were calculated based on the total number of authors whose gender was known. All data were collected and entered into a computer spreadsheet (Microsoft Office Excel 2003). We used descriptive statistics and simple linear regression analysis to test for significance with the aid of NCSS (2004) statistical software for Windows.

\section{Results}

\section{Female authorship of original articles}

A total of 1480 original articles from the British Journal of Psychiatry and 844 original articles from the Psychiatric Bulletin were included in this study. We were unable to determine the gender of the first author in 17 articles $(1.15 \%)$ in the British Journal of Psychiatry and in 1 article $(0.12 \%)$ in the Psychiatric Bulletin. Females were first authors of $33.6 \%$ of articles in the British Journal of Psychiatry and $37.6 \%$ of articles in the Psychiatric Bulletin published during the study period.

The percentage of articles with female first authors in the British Journal of Psychiatry showed a statistically significant increasing trend $(P=0.0128)$ over time (Fig. 1). The lowest female authorship contribution to the British Journal of Psychiatry was in 2002, with $22.5 \%$, while the highest was in 2005, with $42.1 \%$.

In the Psychiatric Bulletin, the lowest female author contribution was in 2005 , with $25.5 \%$; contributions in other years were consistently over $30 \%$, with the highest contribution of $46.8 \%$ achieved in 2004. There was no

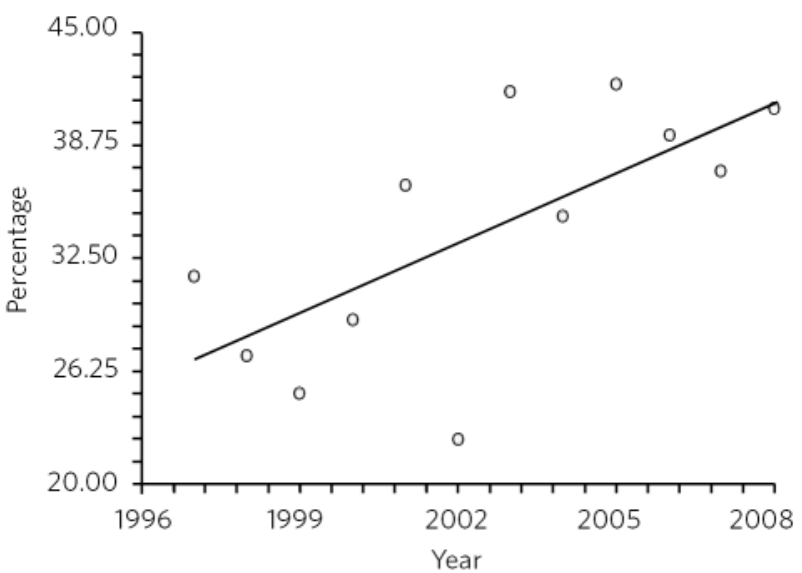

Fig 1 Female first authors in the British Journal of Psychiatry, 1997-2008.

statistically significant increase $(P=0.85)$ in female first author contributions to the Psychiatric Bulletin during the study period (Fig. 2).

Female psychiatrists were responsible for almost half (225/492; 45.7\%) of female first authors' contributions to the British Journal of Psychiatry and almost three-quarters (232/317; 73.2\%) of female first authors' contributions to the Psychiatric Bulletin. The other authors were female researchers with an educational background in psychology, epidemiology, public health, pharmacy, nursing, sociology, health economics, statistics or health administration, and a small number of unknown professions. Some of these researchers hold positions as senior research fellows, readers and professors. Analysis of female first authors of original articles with regard to their geographical region is presented in Table 1 .

\section{Authorship of editorials}

We determined the gender of all the first authors of the 614 editorials in all three journals. Female first authors contributed 75 of a total of 356 editorials (21.1\%) published in the British Journal of Psychiatry and 30 of 193 editorials (15.5\%) in the Psychiatric Bulletin. Female first authors'

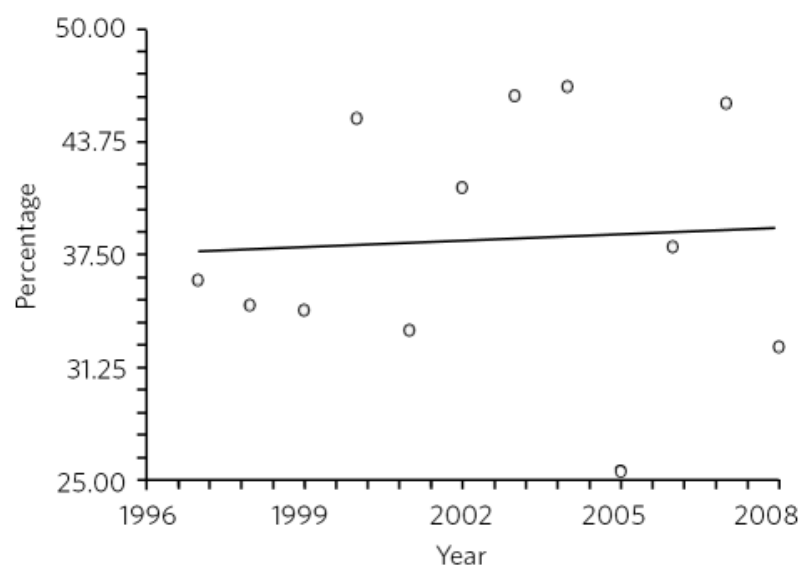

Fig 2 Female first authors in the Psychiatric Bulletin, 1997-2008. 
Table 1 Female first authors of original articles by geographical region

\begin{tabular}{lcccc} 
& \multicolumn{1}{c}{ British Journal of Psychiatry (article total: $N=492)$} & Psychiatric Bulletin (article total: $N=317)$ \\
\cline { 2 - 5 } Region & $n$ & $\%$ & $n$ & $\%$ \\
\hline UK & 302 & 61.4 & 304 & 95.9 \\
\hline Europe & 101 & 20.5 & 10 & 3.2 \\
\hline North America & 49 & 10.0 & 0 & 0 \\
\hline South America & 3 & 0.6 & 1 & 0.3 \\
\hline Africa & 3 & 0.6 & 0 & 0 \\
\hline Asia & 11 & 2.2 & 1 & 0.3 \\
\hline Australia & 23 & 4.7 & 0.3 \\
\hline
\end{tabular}

editorial contributions to Advances in Psychiatric Treatment occurred in only 6 of the 12 years studied, making a total of 9 of 65 editorials $(13.8 \%)$.

\section{Discussion}

In this study, we focused specifically on the trend of first female authorship in the journals of the Royal College of Psychiatrists. The significant increase in women's contributions to the British Journal of Psychiatry mirrored what has been reported in a study by Alonso-Arroyo et al. ${ }^{11}$ Similar increases have also been reported in journals of epidemiology, ${ }^{7}$ intellectual disability (mental retardation) ${ }^{8}$ and surgery. ${ }^{14}$ This could reflect an increase in the number of original articles being submitted by females or a higher acceptance rate of articles by females for publication, or a combination of both factors. However, women appeared underrepresented as first authors in both the British Journal of Psychiatry (33.6\%) and the Psychiatric Bulletin (37.6\%), accounting for about a third of all original articles published over the 12-year study period.

We did not investigate the underlying causes of these gender discrepancies in authorship; however, several studies have explored and discussed reasons for the low proportion of female authorship in scientific journals, including a lower rate of acquiring research grants, ${ }^{7}$ family commitments (in particular child-rearing), ${ }^{15,16}$ and personal career choices, especially with women devoting more of their time to teaching and clinical activities than to research. ${ }^{17}$ Although a number of these factors have not been investigated well, a Swedish study published in Nature in 1997 provided strong evidence of gender discrimination, showing that women in Sweden needed to be two and a half times more productive in terms of publications than their male counterparts to get the same rating for scientific competence. ${ }^{18}$ This is particularly interesting, as this was at the same time that the United Nations officially ranked Sweden as the country that performed best worldwide in terms of gender equality. This apparent discrimination may in turn affect opportunities for research grants, publication and academic progression. Yedidia \& Bickel suggested that gender inequities often occur early in the academic training process and affect career trajectory and, ultimately, the gender distribution and skill mix of the health workforce. ${ }^{19}$

\section{First authors of editorials}

Female underrepresentation was more marked in editorial contributions, where women contributed just one or at most two of every ten editorials published. This significant gender difference in editorial contributions was found in all three journals. This raises concerns regarding the process of editorial selection and publication. Jagsi et al suggested that the low percentage of female editorial contributors in their study may indicate that there is a limited pool of women who have achieved sufficient international recognition and expertise to merit these invitations. ${ }^{2}$ It is, however, difficult to argue that this could account for female first authors producing only $13.8 \%$ of editorials in Advances in Psychiatric Treatment. The fact that there was no editorial by a female first author for 6 of the 12 years studied is of particular concern. This would suggest the importance of further investigation into the likely causes of this finding.

\section{Geographical region of female first authors}

Our study found that the British Journal of Psychiatry (38.6\%) had higher international female authorship representation than the Psychiatric Bulletin (4.1\%). This, in our view, reflects the high impact factor and listing in international journal databases of the long-established British Journal of Psychiatry. The Psychiatric Bulletin appears to provide an opportunity for UK authors to publish, and George et al reported that it is more trainee friendly. ${ }^{20}$ We also noted the high proportion of original articles by international authors from Europe and North America (mainly high-income countries) compared with those from low-income countries. There could be several reasons for this interesting finding, but this study did not investigate the possible causes. However, Patel \& Kim reported that authors from high-income countries have a higher submission rate and their articles are more likely to be accepted than authors from low- and middle-income countries. $^{21}$

\section{Conclusions}

Our study shows that women made significant contributions to published psychiatric research over the study period. However, there is evidence of significant underrepresentation of female first authors in editorials published in the British 
Journal of Psychiatry, the Psychiatric Bulletin and Advances in Psychiatric Treatment. This may reflect gender bias in the process of editorial publication.

\section{Limitations}

There are limitations to our study, including the relatively short duration of the study period. It was not possible to determine the gender of some authors, especially in the British Journal of Psychiatry; however, the percentage is relatively small (less than $2 \%$ ) and did not have a significant influence on the overall findings of our study. British Journal of Psychiatry supplements and International Psychiatry were excluded from the study. We also did not examine the contribution of female co-authors.

\section{Acknowledgements}

We thank Dr D. Rumball, Consultant Psychiatrist, Norfolk and Waveney Mental Health NHS Foundation Trust, Dr O. A. Akenzua, Consultant Psychiatrist, Oxleas NHS Foundation Trust, and Judith Cane, Librarian, Norfolk and Waveney Mental Health NHS Foundation Trust, for their assistance and helpful contributions.

\section{About the authors}

Mercy E. Ochuko-Emore is a Specialty Registrar, and Julian Beezhold is a Consultant Psychiatrist, at the Norfolk and Waveney Mental Health NHS Foundation Trust, Norwich. Jide Morakinyo is a Consultant Psychiatrist at the East London NHS Foundation Trust, London.

\section{References}

1 Killaspy $H$, Johnson S, Livingston G, Hassiotis A, Robertson M. Women in academic psychiatry in the United Kingdom. Psychiatr Bull 2003; 27: $323-6$.

2 Jagsi R, Guancial EA, Worobey CC, Henault LE, Chang Y, Starr R, et al. The 'gender gap' in authorship of academic medical literature: a 35-year perspective. N Engl J Med 2006; 355: 281-7.

3 Howard L. Women in academic psychiatry. Psychiatr Bull 2003; 27: 321-2.

4 Greenfield S, Peters J, Lane N, Rees T, Samuels G. SET Fair: A Report on Women in Science, Engineering and Technology. Department of Trade and Industry/HMSO, 2002

5 McSweeney FK, Donahoe P, Swindell S. Women in applied behavior analysis. Behav Anal 2000; 23: 267-77.
6 Reiser LW, Sledge WH, Fenton W, Leaf P. Beginning careers in academic psychiatry for women: 'Bermuda Triangle'? Am J Psychiatry 1993; 150: 1392-7.

7 Dickersin K, Fredman L, Flegal K, Scott JD, Crawley B. Is there a sex bias in choosing editors? Epidemiology journal as an example. JAMA 1998; 280: $260-4$.

8 Porter CL, Christian L, Polling A. Participation of women as authors and editors in journals concerned with mental retardation and related topics. Ment Retard 2003; 41: 1-6.

9 Barnett RC, Carr P, Boisnier AD. Relationship of gender and career motivation to medical faculty members' production of academic publications. Acad Med 1988; 73: 180-6.

10 Leibenluft E, Dial TH, Haviland MG, Pincus HA. Sex differences in rank attainment and research activities among academic psychiatrists. Arch Gen Psychiatry 1993; 50: 896-904

11 Alonso-Arroyo A, Gonzalez-Alcaide G, Bolanos Pizarro M, Castello Cogollos L, Valderrama-Zurian JC, Aleixandre-Benavent R. Gender analysis of papers published in Actas Espanolas de Psiquiatria (19992006). Actas Esp Psiquiatr 2008; 36: 314-22.

12 Opgenhaffen M, Vansteelandt K, Germeau P, Pieters G. Toename van het percentage vrouwelijke auteurs in de internationale psychiatrische vakliteratuur sinds 1970. [Increase in the percentage of female authors in the international psychiatric literature since 1970.] Tijdschr Psychiatr 2008; 50: 419-23.

13 Bhattacharyya N Shapiro NL. Increased female authorship in otolaryngology over the past three decades. Laryngoscope 2000; 110: 358-61.

14 Kurichi JE, Kelz RR, Sonnad SS. Women authors of surgical research. Arch Surg 2005; 140: 1074-7.

15 Wilson S, Eagles JM. The feminisation of psychiatry: changing gender balance in the psychiatric workforce. Psychiatr Bull 2006; 30: 321-3.

16 Carr PL, Ash AS, Friedman RH, Scaramucci A, Barnett RC, Szalacha LEDM, et al. Relation of family responsibilities and gender to the productivity and career satisfaction of medical faculty. Ann Intern Med 1998; 129: 532-8.

17 Buckley LM, Sanders K, Shih M, Hampton CL. Attitude of clinical faculty about career progress, career success and recognition and commitment to academic medicine: result of a survey. Arch Intern Med 2000; 160: 2625-9.

18 Wenneras C, Wold A. Nepotism and sexism in peer-review. Nature 1997; 387: $341-3$.

19 Yedidia MJ, Bickel K. Why aren't there more women leaders in academic medicine? The views of clinical department chairs. Acad Med 2001; 76 453-65.

20 George S, Dhaya D, Oyebode F. Five-year study (2000-2004) of trainees' publications in the Psychiatric Bulletin. Psychiatr Bull 2006; 30: 306-8.

21 Patel V, Kim Y-R. Contribution of low- and middle-income countries to research published in leading general psychiatric journals, 2002-2004. Br J Psychiatry 2007; 190: 77-8. 